\title{
Perforation of Bicuspid Aortic Valve mimicking Trileaflet Aortic Valve on Transesophageal Echocardiography
}

\author{
Soumendu Pal
}

\begin{abstract}
Endocarditis of bicuspid aortic valve (BAV) can lead to valve perforation and result in severe aortic incompetence. Perforation of valve cusps should be considered in the differential diagnosis of BAV patients presenting with $A R$, and the condition should not be mistaken as a regurgitant trileaflet $\mathrm{AV}$ on transesophageal echocardiography (TEE). Accurate preoperative characterization of the mechanism of aortic regurgitation by TEE is important for determining the type of surgical repair.
\end{abstract}

Keywords: Bicuspid aortic vlave, Endocarditis, Transesophageal echocardiography.

How to cite this article: Pal S. Perforation of Bicuspid Aortic Valve mimicking Trileaflet Aortic Valve on Transesophageal Echocardiography. J Perioper Echocardiogr 2014;2(2):77-79.

Source of support: Nil

Conflict of interest: None declared

\section{CASE REPORT}

A 38-year-old, male patient was admitted with history of dyspnea on exertion (DOE), grade II, associated with palpitations for 2 years. There was recent aggravation of symptoms to DOE grade III for 1 month. On investigation, Transthoracic echocardiography (TTE) reported thickened aortic valve (AV) with severe eccentric aortic regurgitation (AR) and mild aortic stenosis. There was an oscillating mass attached to the under surface of the $\mathrm{AV}$ cusps. There was suspicion of vegetation attached to the AV along with a possible perforation of a valve cusp. The left ventricle (LV) was dilated (LVIDd $73 \mathrm{~mm}$, LVIDs $45 \mathrm{~mm}$ ) and mildly hypertrophied. The aortic annulus, aortic root or ST junction were not dilated. Their dimensions were 26,38 and $34.5 \mathrm{~mm}$ respectively. The mitral and tricuspid valves were normal.

\section{Associate Consultant}

Department of Cardiac Anesthesia, Fortis Memorial Research Institute, Gurgaon, Haryana, India

Corresponding Author: Soumendu Pal, Associate Consultant Department of Cardiac Anesthesia, Fortis Memorial Research Institute, Gurgaon, Haryana, India, Phone: 012-44962200 e-mail: drsoumendupal@gmail.com
He was posted for elective AV replacement/repair. In the intraoperative transesophageal echocardiography (TEE), the midesophageal (ME) AV long-axis view (Fig. 1, Video 1) showed that the leaflets were flail and prolapsing in the left ventricular outflow tract (LVOT) during diastole. The ME AV long-axis view with color flow Doppler (CFD) (Fig. 2) showed a large turbulence filling up the LVOT in diastole and thus confirmed severe AR. There was no evidence of any vegetation on the valve as reported in TTE. The flail leaflets may have given the appearance of the oscillating mass reported in TTE. The severity of AR was further quantified by pressure half time (140 msecs) obtained from deep transgastric longaxis view and also by demonstrating holodiastolic flow reversal in the descending aorta.

The ME AV short-axis view showed a bicuspid AV (BAV) (Fig. 3, Video 2). There was no thickening or calcification of the leaflets. There was no coaptation defect of the valve leaflets sufficient to cause such a large regurgitation. Further interrogation of the valve leaflets by slight manipulation of the probe showed that there was a large, triangular-shaped perforation in the larger valve cusp which was causing severe AR (Fig. 4, Video 3). It may be noted that a regurgitant trileaflet $\mathrm{AV}$ with a coaptation defect has a similar, triangular shaped orifice. The perforated $\mathrm{BAV}$, thus, resembled a trileaflet $\mathrm{AV}$ with a large coaptation defect (Fig. 5), which is a much more common cause of severe AR.

\section{DISCUSSION}

Bicuspid AV (BAV) occurs in 0.5 to $2 \%$ of the population and serious complications will develop in $33 \%$ of patients with BAV. ${ }^{1}$ The important clinical consequences of BAV disease are valvular stenosis, regurgitation, infective endocarditis and aortic complications, such as dilation and dissection. Aortic regurgitation occurs in the presence of a BAV usually from cusp prolapse, fibrotic retraction, or dilation of the sinotubular junction. Endocarditis can also lead to valve perforation or destruction and result in severe aortic incompetence. Recent estimates of the incidence of endocarditis are $2 \%{ }^{2}$

The bicuspid valve is typically made of two unequalsized leaflets. The larger leaflet has a central raphe or 


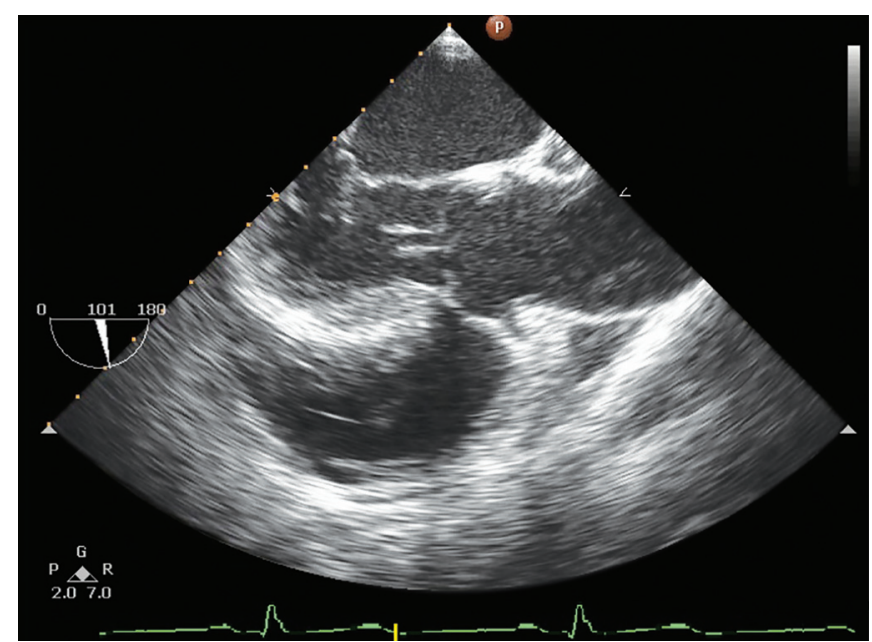

Fig. 1: The midesophageal aortic valve long-axis view showing the flail valve leaflets in diastole

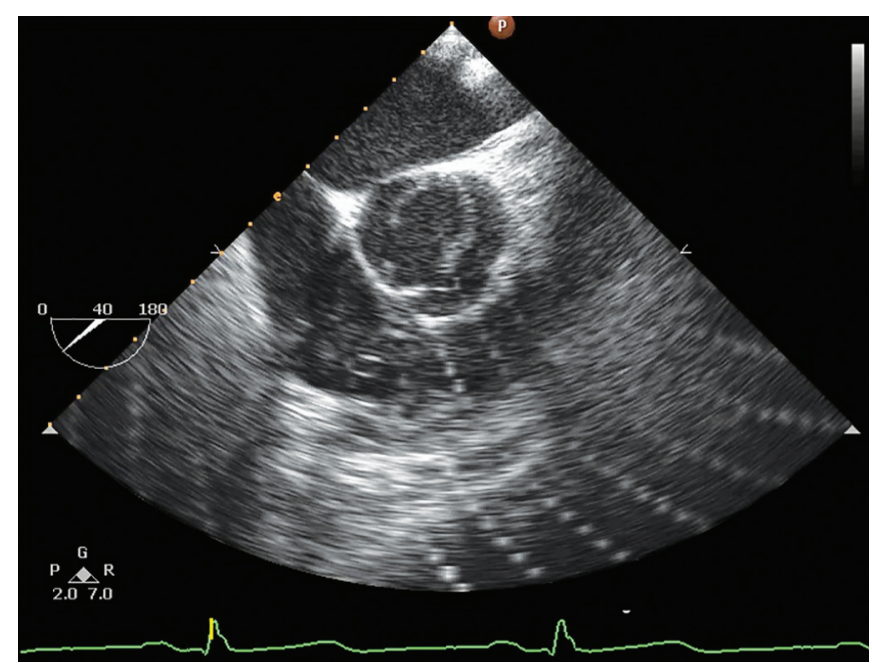

Fig. 3: The midesophageal aortic valve short-axis view showing the bicuspid AV

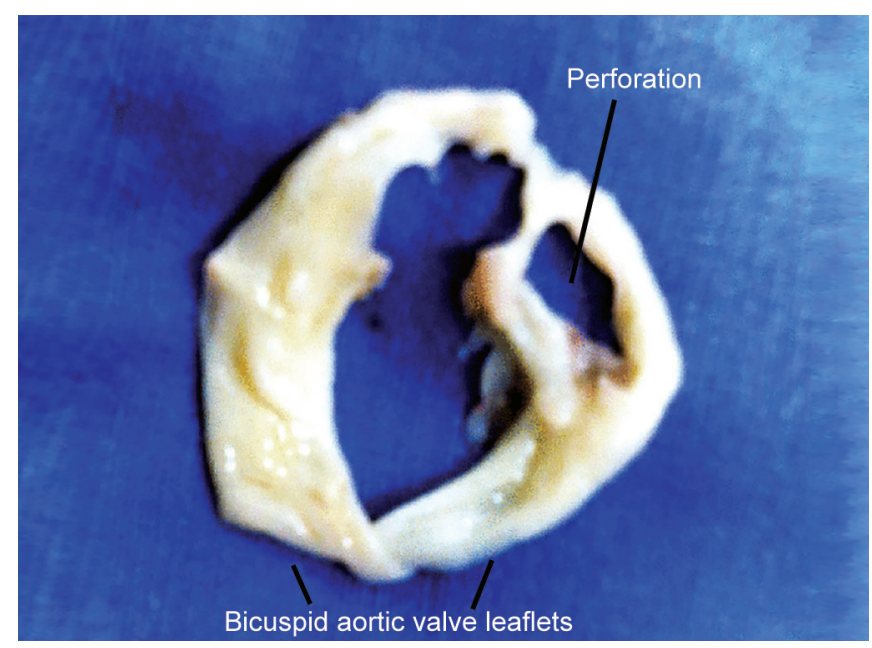

Fig. 5: Surgical specimen of the bicuspid aortic valve with perforation

ridge that results from fusion of the commissures. The most common pattern involves fusion of the right and left coronary cusps. ${ }^{3}$ A large perforation will result in severe aortic regurgitation. In BAV, when the larger

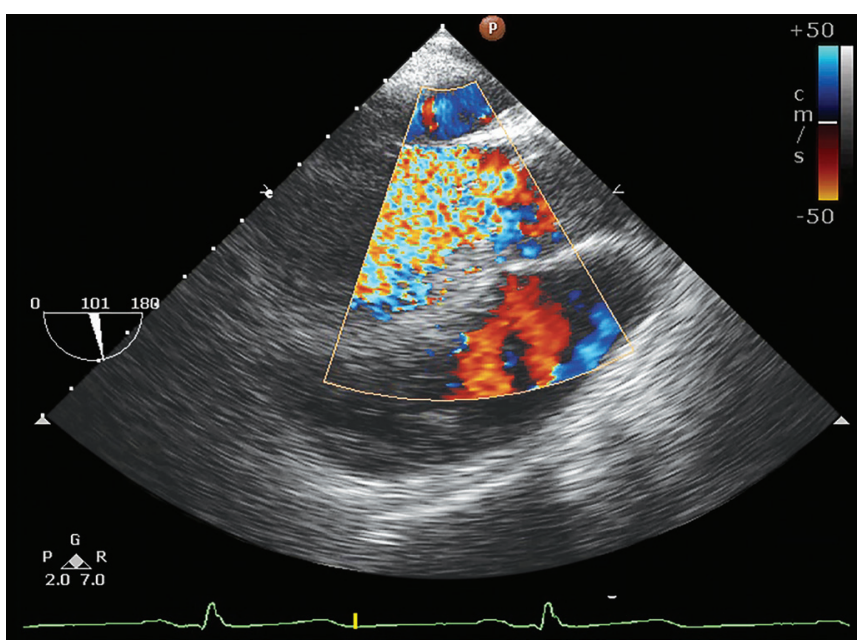

Fig. 2: The ME AV long-axis view with color flow Doppler (CFD) showing severe AR

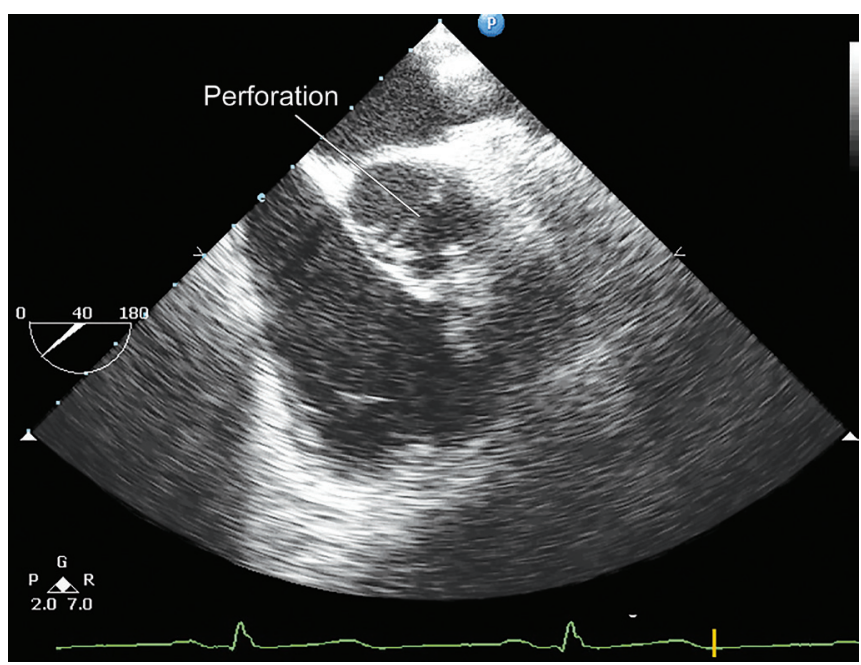

Fig. 4: The midesophageal aortic valve short-axis view showing a triangular perforation in the bicuspid $\mathrm{AV}$

cusp is perforated due to endocarditis, it gives a trileaflet appearance to the BAV on TEE.

Le Polain de Waroux et $\mathrm{al}^{4}$ concluded from their study that the functional anatomy of AR defined by TEE is strongly and independently predictive of reparability and postoperative outcome. Therefore, AR lesions assessed by TEE represent essential information for clinical decision-making. A trileaflet AV with severe AR with normal leaflets will suggest a type Ic defect in which the mechanism leading to AR is dilatation of functional aortic annulus with outward displacement of the leaflets with a decrease of central coaptation. This condition can be treated by subcommissural annuloplasty. On the other hand, perforation of a cusp is a type Id defect which can be repaired by autologous or bovine pericardial patch. ${ }^{5}$ Although this patient was not considered suitable for $\mathrm{AV}$ repair and underwent $\mathrm{AV}$ replacement, accurate preoperative characterization of the mechanism of AR by TEE is very important for determining the type of surgical repair best suited for the case. Perforation of 
valve cusps should be considered in the differential diagnosis of BAV patients presenting with $A R$, and the condition should not be mistaken as a regurgitant trileaflet AV on TEE.

\section{REFERENCES}

1. Fedak PWM, VermaS, David TE, Leask RL, Weisel RD, Butany J. Clinical and pathophysiological implications of a bicuspid aortic valve. Circulation 2002;106(8):900-904.

2. Michelena HI, Desjardins VA, Avierinos JF, Russo A, Nkomo VT, Sundt TM, Pellikka PA, Tajik AJ, Enriquez-Sarano M. Natural history of asymptomatic patients with normally functioning or minimally dysfunctional bicuspid aortic valve in the community. Circulation 2008;117(21):2776-2784.

3. Siu SC, Silversides CK. Bicuspid aortic valve disease. J Am Coll Cardiol 2010;55(25):2789-2800.

4. Le Polain de Waroux JB, Pouleur AC, Goffinet C, Vancraeynest D, Van Dyck M, Robert A, Gerber BL, Pasquet A, El Khoury G, Vanoverschelde JLJ. Functional anatomy of aortic regurgitation accuracy, prediction of surgical repairability, and outcome implications of transesophageal echocardiography. Circulation 2007;116(11 Suppl):1264-1269.

5. de Kerchove L, El Khoury G. Anatomy and pathophysiology of the ventriculoaortic junction: implication in aortic valve repair surgery. Ann Cardiothorac Surg 2013;2(1):57-64. 